\title{
ELS REDEMPTORS DE CAPTIUS: MOSTOLAFS, EIXEES \\ O ALFAQUECS (SEGLES XII-XIII)
}

\author{
Maria Teresa Ferrer $i$ Mallol
}

La confrontació amb l'islam a les nostres terres, en guerra oberta o en accions de cors o de saltejament fronterer, comportà la captivitat per a moltes persones d'ambdós bàndols, que queien presoneres en aquestes accions.

Tant entre els cristians com entre els sarraïns, els parents i amics dels infortunats que havien caigut en captivitat feien tant con podien per ajudar-los a recuperar la llibertat.

Per això, tal com ja ho indicà Ramos Loscertales a la seva obra sobre aquest tema, des de molt aviat els propietaris de captius veieren que sovint resultava més beneficiós revendre el captiu al seu Jloc d'origen que no pas vendre'l al preu de mercat. A més, les facilitats donades per a la redempció de captius sarrains repercutien en facilitats per a la redempció de captius cristians ${ }^{1}$.

Des de molt aviat, doncs, s'organitzà aquesta revenda per mitjà de persones especialitzades a negociar rescats i retornar els captius a llur terra d'origen. Aquestes persones foren anomenades, en terres

1 J.M. Ramos Loscertales, El cautiverio en la Corona de Aragón durante los siglos XII, XIV y XV, Saragossa 1915, pp. 135.136. 
catalanes, mostolafs (o motolafs), i més tard eixees o alfaquecs, i llur ofici mostalafia, eixeatge o alfaquequeria.

Com que de fet la redempció de captius tenia una vessant pública, ja que afectava les relacions exteriors, concretament allò que hom denominava pau i guerra, que era una de les regalies del príncep, és explicable que la mostalafia fos un monopoli dels comtes de Barcelona i després dels reis de la Corona catalano-aragonesa.

Els comtes $\mathrm{i}$ els reis cediren aquest monopoli a determinades persones o famílies a canvi de prestacions pecuniàries o bé a cens. En el segon cas, si bé els documents concreten la quantitat pagada en el moment de la concessió, no citen el que calia pagar de cens més que amb una referència imprecisa, com per exemple «salvis meis directis que recto usatico mihi [al comte] inde exire debent», tal com ho diu una concessió de 1144. Aquests drets o directis devien ésser prou substanciosos per permetre que el concessionari de la mostalafia pogués recuperar en un temps raonable, que no és especificat, 50 morabatins dels 150 que havia pagat per la concessió $\mathrm{i}$ que el comte acordà retornar- $\mathrm{li}^{2}$.

La remuneració pagada al mostolaf és desconeguda. Els documents del segle XIV fan referència als honoraris acostumats, però sense concretar quins eren ${ }^{3}$. A Aragó, el fur de Terol establí per a l'eixea un $10 \%$ del rescat $i$, si es tractava d'intercanvi, una moneda d'or jucefia i la mateixa quantitat per a despeses de conducció i manteniment del captiu fins a lliurar-lo als familiars ${ }^{4}$. La remuneració fou similar a Castella, i cal suposar que en terres catalanes no degué ésser gaire diferent 5 .

Amb tot, és segur que era una feina ben remunerada i és natural que fos així, ja que un mostolaf o eixea havia de tenir unes qualitats

2 Cf. Apèndix, doc. 2.

3 ACA, C, reg. 292, f. 20, publ. per J. M. RAMOs LosCerTALES, p. 155, nota 9 i ACA, C, reg. 504, f. 1080 v (1329, maig, 4).

4 J. TORRES FONTES, Los alfaqueques castellanos en la frontera de Granada, Homenaje a Don Agustín Millares Carlo, II, Madrid 1975, p. 112. També, J.M. RAmos LOSCERTALES, p. 155, C. VERLINDEN, L'esclavage dans l'Europe médiévale, 1. Péninsule ibérique, France, Bruges 1955.

5 J. TORRES FONTES, p. 112. 
molt especials. Havia de tenir les virtuts del diplomàtic i al mateix temps les del mercader. De diplomàtic, perquè havia de tenir tractes prudents i discrets amb els estaments oficials dels països on havia d'actuar, països amb els quals hi havia sovint relacions tenses o estat de guerra. De mercader, perquè la redempció de captius era, de fet, una compra-venda que calia plantejar, negociar i regatejar com una altra operació mercantil qualsevol.

A Castella, les Partides exigien honorabilitat i fortuna a aquests intermediaris perquè poguessin respondre dels rescats que rebien si, per un cas, els venia el pensament d'apropiar-se' $1 s^{6}$. A Catalunya sabem que, el segle XIV, hom els exigia fiança, i que havien de prestar jurament, en mans d'un oficial reial, d'exercir el càrrec bé i lleialment?

Gaudien d'immunitat diplomàtica i tenien pas lliure per les fronteres, fins i tot en temps de guerra, ells i llur rècula i la moneda que treien per pagar els rescats. Era costum, però, que el país d'origen de l'eixea demanés prèviament per a ell un salconduit i guiatge al monarca del país on havia d'actuar8.

Les $P$ artides castellanes assenyalaven, entre les condicions que havia de tenir l'eixea, el coneixement de llengües, a fi que poguessin entendre's directament amb l'altra part negociadora i no poguessin ésser enganyats 9 . Era una condició exigible en qualsevol lloc i també en terres catalanes. Els primers eixees o mostolafs dels quals hi ha notícia en terres catalanes són jueus, que aconseguiren el càrrec potser per llur coneixement de l'àrab, molt freqüent entre els jueus ${ }^{10}$. En alguna altra ocasió, el càrrec recaigué en mercaders musulmans estrangers, els quals, naturalment, coneixien l'àrab, però havien d'actuar conjuntament amb un cristià ${ }^{11}$. Altres cops recaigué

6 J. TORRES FONTES, p. 102-103,

7 ACA, C, reg. 83, f. 61 v cit. per J.M. RAmos LOSCERTALES, El cautiverio en la Corona de Aragón.... p. 156 i ACA, C, reg. 504, fol. 108v (1329, maig, 4) i reg. 506, fols. $68 \mathrm{v}-69 \mathrm{r}(1331$, juliol, 9$)$.

8 ACA, C. cr. Jaume II, núm. 2461 (1305, juny, 9).

9 J. TORRES FONTES, p. 102.

$10 \mathrm{Cf}$. Apèndix, doc. 1.

11 Cf. Apèndix, doc. 10. 
en mercaders catalans que traficaven en països musulmans i que, presumiblement, també el coneixien. El segle XIV, consta que alguna vegada els eixees de la Corona catalano-aragonesa hagueren d'actuar conjuntament amb l'alfaquec nomenat pel rei de Granada. Un dels eixees d'aquest segle, Pere Martínez de Mora, ostentà també el càrrec de torsimany de la casa del rei, cosa que sembla que indica que coneixia l'àrab ${ }^{12}$.

Les Partides castellanes fan referència, a més, a l'obligació de l'eixea de portar l'ensenya reial, si era de nomenament reial, o la senyera municipal, si havia estat nomenat per un municipi, perquè fos coneguda la seva condició. És ben probable que en terres catalanes, s'actués d'idèntica manera. Les mateixes Partides indiquen també que l'eixea havia de circular per camí principal i que, abans de sortir de viatge, havia de detallar en carta pública tot el que portava $^{13}$. L'obligació de circular per camins generals ens consta només en el cas d'un eixea que havia de conduir sarraïns emigrants ${ }^{14}$, però és ben probable que fos idèntica quan es tractava de captius o d'excaptius. No tenim constància, en canvi, de l'obligació de fer carta pública de tot allò que duia. Tenim constància, però, d'altres coses; per exemple, que era costum d'alfaquequeria que l'eixea portés desferrats els captius cristians o sarrainns que es redimien, és a dir, sense cadenes, i que aquests havien d'anar segurs sota la seva guardals.

Tampoc no ens consta que els eixees de terres catalano-aragoneses tinguessin prohibit d'exercir simultàniament el comerç o transport de mercaderies amb la tasca de redempció de captius, tal com succeìa a Castella, almenys segons la lletra de les Partides ${ }^{16}$. La concessió de la mostalafia o eixeatge a tres sarraïns de Tànger el 1227 esmenta expressament l'autorització a un d'ells per mercadejar a València ${ }^{17}$. Al contrari, la concessió de 1105 als jueus Mosse, Iafia, Honen i Abotaib els dóna la facultat de vetar la presència a bord de

12 ACA, C, reg. 504, fol. $108 v$ i reg. 506, fols. $68 v-69 r$, ja citats.

$13 \mathrm{~J}$. TORRES FONTES, p. 103.

14 ACA, C, reg. 949, fols. 130v-131r (1339, juny, 9).

$15 \mathrm{Cf}$. els documents citats a la nota 12 .

$16 \mathrm{~J}$. TORRES FONTES, p. 103.

17 Cf. Apèndix, doc, 10. 
llur nau de jueus o cristians que anessin a mercadejar, cosa que significaria que eren partidaris de separar mercaderia i redempció de captius $^{18}$. Però les notícies posteriors, del segle XIV, sembla que indiquen que prevalgueren els criteris més liberals de permetre als eixees l'exercici de la mercaderia. Així, per exemple, un privilegi de concessió temporal de l'eixeatge a Valeri Vilar posà sota el guiatge reial totes les coses que portessin ell i el seu soci, a més dels captius i dels diners del rescat, llevat que fossin mercaderies prohibides, cosa que permet suposar que podien portar altres mercaderies que no fossin prohibides ${ }^{19}$. També, en realitat, els alfaquecs castellans exerciren simultàniament ambdues coses, almenys el segle XV, com ho demostra un text recollit per Ramos Loscertales de la Crónica de Miguel Lucas, referent a un alfaquec de Jaén, anomenat Alonso el Gordo, que havia de portar a Granada moros rescatats «y otras mercadurías» 20 .

El nomenament més antic conegut per ara d'un mostolaf (o motolaf), publicat fa molts anys per F. Fita, és el dels quatre jueus anomenats Mosse, Iafia, Honen i Abotaib, al qual ja ens hem referit. El mes d'abril de 1105, Ramon Berenguer III de Barcelona els concedí en exclusiva l'encàrrec de tornar a l'Espanya musulmana els esclaus sarraïns alliberats; els quatre jueus, que havien liurat al comte la quantitat de 12 lliures de plata, no podien ésser desposseïts del càrrec si el comte no els retornava aquesta quantitat. La via marítima sembla que era l'escollida per portar a destinació els sarraïns alliberats, ja que es parla de la nau dels jueus, en la qual aquests es reservaren el dret d'admetre mercaders jueus o cristians, o no ${ }^{21}$.

També és coneguda, per mitjà d'un trasllat més tardà, del 1208 , una concessió de la mostalafia feta pel comte Ramon Berenguer IV, el 12 de gener de 1144. Fou publicada al volum IV de la «Colección de Documentos Inéditos del Archivo de la Corona de Aragón»,

$18 \mathrm{Cf}$. Apèndix, doc. 1.

19 J, VINCKE, «Konigtum und Sklaverei im aragonischen Staatenbund wärend des 14 Jahrhunderts», Gesammelte aufsätze zur Kulturgeschichte Spaniens 25 band, 1970, p. 46.

20 J. M. Ramos, p. 155.

21 Cf. Apèndix, doc. 1. 
però no ens consta que hagi estat comentada. Un altre trasllat d'aquesta concessió, del 1198, es conserva a l'Arxiu de la Catedral de Barcelona i és el que publiquem a l'apèndix documental. El beneficiari de la concessió fou el mercader barceloní Arnau Pere d'Arcs, que pagà al comte Ramon Berenguer IV 150 morabatins d'or per aquesta causa, 50 dels quals havien d'ésser recuperats pel concessionari del dret que el comte retenia a la dita mostalafia. Si ell o els seus successors trencaven aquesta concessió, el comte s'obligava a l'esmena del doble de la quantitat pagada, que era molt considerable i demostra que l'activitat del mostolaf era molt rendible 22 .

Sembla que la concessió a Arnau Pere d'Arcs era vàlida per a tota la terra que posseia llavors el comte, puix que donava «totam ipsam amoctalafiam» íntegra i sense cap disminució. Ben aviat, però, les terres del comte s'estengueren fins a Tortosa, presa el 1148, i poc després el comte cedí la mostalafia d'aquest territori a un burgès de Tortosa, que podria ésser Arnau de Robió, o el seu pare, ja que després tingué un plet per causa de la mostalafia de Tortosa. Ignorem quina era exactament la delimitació d'aquesta nova mostalafia, però documents posteriors permeten de suposar que era de Tarragona a Tortosa i que comportava també la del regne de València, encara per conquerir.

Com que Guillem Ramon de Montcada Dapifer era senyor d'un terç de Tortosa, no trigà a reclamar la part que li corresponia dels diners pagats per la cessió de la mostalafia. El comte Ramon Berenguer IV s'hi resistí, perquè al-legà que la demarcació de la mostalafia era més àmplia que el senyoriu de Tortosa, i aquest fou un dels greuges presentats per Guillem Ramon de Montcada contra el comte. Sembla que el plet fou jutjat a la cúria comtal, entre 1148 i 1162. La Cúria decidí que el comte pagués a Guillem Ramon de Montcada la part de la mostalafia que pertoqués a la ciutat de Tortosa, ja que d'aquí se'n treia molt de profit, i que Guillem Ramon de Montcada cobrés també la part que li correspongués del que pagaven els captius (suposem que era l'impost sobre els captius sar-

22 Cf. Apèndix, doc. 2. 
raïns que es redimien) i del que pagava el mostolaf per la mostalafia 23 .

És possible que estigués en relació amb aquest plet i amb la seva solució un pergamí del 1184, en el qual Ramon de Montcada, fill de l'anterior, i la seva muller, Ramona, reconegueren a Amau de Robió $i$ als seus germans, Guillem i Berenguer, la quarta part de l'eixea de Tortosa i la quarta part de l'eixea de València, amb la qual cosa conclogueren la discussió que mantenien. Subratllem que és la primera vegada que apareix la paraula eixea als documents catalans, substituint la de mostalafia, que quedarà molt relegada els segles XIII i XIV24.

Uns anys després de la concessió de la mostalafia a Amau Pere d'Arcs, pel novembre de 1178, el càrrec fou novament cedit pel rei Alfons el Trobador al barceloní Bernat Marcús i als seus successors, per 500 sous de Barcelona, la meitat del que havia costat a Arnau Pere d'Arcs. Bernat Marcús quedava autoritzat a portar amb la seva nau captius sarraïns a llurs terres d'origen per redimir-los, i a rescatar cristians captius en terres sarraïnes. Hem de fer notar que les terres sarraïnes citades en concret com a llocs on hauria de portar els sarraïns redimits eren Bugia i Ceuta, malgrat que l'afegit «et in omni alia terra sarracenorum» dóna a la concessió un caràcter general. Cap batlle reial no podria posar impediments a Bernat Marcús per salpar amb la seva nau, quan estigués preparada.

La concessió a favor de Bernat Marcús no feia cap referència a la que havia estat feta anteriorment a Arnau Pere d'Arcs, com si ja hagués caducat. És possible que el concessionari hagués mort i que els seus hereus no estiguessin en disposició, en aquells moments, de fer cap reclamació 25 .

No sabem si ja es relacionava amb una reclamació d'aquests hereus la nova donació de la mostalafia signada pel mateix rei Alfons

23 «Colección de documentos inéditos del Archivo de la Corona de Aragón» IV, doc. LI, pp. 118-119 i doc. CXLVII, pp. 350-351. Sobre els Montcada i llur senyoriu de Tortosa, compartit amb els comtes o reis i els Templers, cf. L. PAGA. ROLAS, La Comanda del Temple de Tortosa: primer periode (1148-1213), Tortosa 1984, pp. 150-151.

24 Cf. Apèndix, doc. 4.

25 Cf. Apèndix, doc. 3. 
set anys després, per l'abril de 1185 . Els concessionaris eren ara el mateix Bernat Marcús i Bernat Adarró, que per documents posteriors sabem que es casà amb una néta d'Arnau Pere d'Arcs, anomenada Berenguera. Ignorem si l'aparició d'aquest Bernat Adarró al costat de Bernat Marcús, com a concessionaris de la mostalafia, fou una manera de reparar l'oblit dels drets dels descendents d'Arnau Pere d'Arcs. El cas és que el rei no declarà en el document que hagués rebut cap quantitat de diners per la concessió, ni de Bernat Marcús, que ja havia pagat el 1178, ni de Bernat Adarró 26 .

Aquesta vegada el rei subratllava que els concessionaris tenien el monopoli del transport dels sarraïns redimits a totes les seves terres, llevat de la mostalafia de València, que quedava atribuïda al territori català fronterer comprés entre Tarragona i Tortosa i que el rei reservava perquè ja l'havia concedida. Els concessionaris d'aquesta altra mostalafia de les terres meridionals havien d'ésser Ramon de Montcada i els Robió, ja que la concòrdia entre ells per l' exeam de Tortosa i la de València és justament del 1184, com ja hem dit. No pas gaire més tard, però, canvià de mà.

En efecte, consta que, el 1206, la mostalafia de València pertanyia a Berenguera, la muller de Bernat Adarró i néta d'Arnau Pere d'Ares. Possiblement no havia vist reconeguts els seus drets en tota la mostalafia fins el 1198. Aquest any, en efecte, Pere el Catòlic confirmà a favor d'ella la donació de la mostalafia, tal com l'havia feta Ramon Berenguer IV a Arnau Pere d'Arcs. Per la confirmació, el rei percebé 50 morabatins. Atès que no era imaginable que una dona exercís directament la mostalafia, el document puntualitzava que el càrrec podia ésser regit per substituts designats per ella, amb la condició que fossin persones discretes i que sabessin regir el càrrec. Per a més seguretat, el rei sotmeté aquesta qüestió a la inspecció de quatre prohoms barcelonins 27 .

El 1206, Berenguera Adarró, muller de Bernat Adarró, cedí la mostalafia al seu fill Amau el dia del seu casament i aquest la cedí, al seu torn, a la seva mare en usdefruit vitalici contra prestació d'un

$26 \mathrm{Cf}$. Apèndix, doc. 5.

27 Cf. Apèndix, doc. 6. 
petit cens anual de mitja lliura de cera. És en aquest document notarial que hom fa referència a la mostalafia de Barcelona i València, referència que no apareixia ni a la concessió del rei Pere ni a la de Ramon Berenguer IV, a la qual aquesta es remeté. En aquest moment, doncs, ambdues mostalafies tornaven a veure's reunides en una sola mà 28 .

Suposem que la donació de Berenguera Adarró al seu fill devia ésser destinada a assegurar la continuitat de la mostalafia dins de la familia, perquè el profit material que li havia de produir era ben migrat. Si les altres donacions que els seus pares li feren amb motiu del seu matrimoni foren del mateix estil, és comprensible que un any després es trobés a la misèria, fins a tal punt que el rei intervingué en la qüestió per ordenar als pares que lliuressin al fill 500 monedes d'or, obligant llurs béns, perquè pogués afrontar els seus deutes 29 .

Ignorem com quedà la concessió dels Adarró quan, uns quants anys després, el regne de València fou conquerit per Jaume I.

No tenim més notícies de la concessió de la mostalafia durant seixanta anys. En aquest temps, la paraula mostalafia comença a desaparèixer del llenguatge de la cancelleria, que adopta per designar el càrrec de mostolaf les formes eixea i eixeatge. Encara el 1214, però, un préstec marítim atorgat sobre la base d'un captiu que era portat a Bona, segurament per ésser redimit, esmenta el costum de «mostalafia» en el trajecte entre Barcelona i Bona, costum que creiem que ha de fer referència al fet que la mort del captiu durant el trajecte anul-lava el deute, constituït pel rescat que calia cobrar a Bona ${ }^{30}$.

Del 1267 coneixem la concessió del càrrec d'eixea amb caràcter vitalici a favor de Joan Cambra, fill de Domingo Cambra, ciutadà de València, concessió que no havia de tenir efecte fins a la mort del pare, que ostentava el càrrec llavors. Aquesta concessió, que fou

$28 \mathrm{Cf}$. Apèndix, docs. 7 i 8.

29 ACB (Arxiu de la Catedral de Barcelona), Cartes reials 1-4.

30 A. GARCIA I SANZ i M.T. FERRER I MALLOL, Assegurances i canvis maritims a la Barcelona medieval, Institut d'Estudis Catalans, Barcelona 1983, doc. 7 i pp. 37-38 de l'estudi. 
publicada per Vincke, té la particularitat que és limitada territorialment, és a dir, que era vàlida només per a la meitat meridional del regne de València, des de la capital fỉns a la frontera de Múrica. L'expansió territorial impulsada per Jaume I exigia segurament més d'un eixea al regne de València, com abans havia passat a Catalunya, per tal d'atendre la feina, que devia haver augmentat moltíssim i més tenint en compte que les guerres que havien permès aquesta expansió havien produït, sens dubte, un gran nombre de captius, tant per banda sarraina com cristiana, encara que, evidentment, n'hi hagué més de sarraïns que dé cristians.

Entre les prerrogatives del càrrec, la concessió esmenta la de poder treure captius i menar la rècula sota el guiatge especial del rei, tasques que podia acomplir tant directament com per mitjà d'un substitut. Així com els primers mostolafs o motolafs, els nomenaments dels quals hem comentat, fan l'efecte d'haver desenvolupat llur tasca principalment per via marítima i sobretot amb els països barbarescos, el de Joan Cambra sembla adreçat predominatment a l'àmbit del regne de Granada. La cita de la rècula, la caravana que portava els captius i les mercaderies a Granada sota la direcció de l'eixea, sembla que així ho indica ${ }^{31}$.

El mateix rei Jaume I concedí encara altres nomenaments d'eixees, entre ells un, que no hem trobat, a favor d'uns sarraïns de Tànger, Alí i Muhammad Abcocon, fills d'Ibrahim, que havien d'actuar conjuntament amb el valencià Jaume Farfal. Vincke publicà la confirmació d'aquest nomenament, atorgada per Pere el Gran el 3 d'agost de 1277. En aquest cas, tots tres eixees són anomenats novament motolafs, com en els documents més antics. Podien treure i redimir captius, tant sarraïns com cristians de terres sarraïnes, i un d'ells, Muhammad, fou autoritzat a residir a València dins del clos de les muralles i a usar la seva casa com a dipòsit de les mercaderies, coses, totes dues, que devien ésser excepcionals, ja que les sarraïns havien d'allotjar-se al raval sarraí i les mercaderies havien d'ésser dipositades, generalment, als alfòndecs, que eren al mateix temps hostals. Aquest privilegi no dispensava, però,

31 Cf. Apèndix, doc. 9. 
Muhammad Abcocon de pagar els impostos establerts per a aquestes mercaderies ${ }^{32}$.

Com dèiem, aquest és el darrer document que hem vist en el qual els eixees són anomenats motolafs o mostolafs. Després, la paraula mostalafia quedà per designar l'impost que el rei cobrava als sarraïns cada any pel dret de residir a les seves terres o el que pagaven si decidien marxar-ne. Així es desprèn, almenys, dels documents coneguts per ara.

De fet, durant tot el segle XII, aquest nom de mostalafia tenia ja el sentit d'impost. Pel juny de 1209, Guillem Durfort, que era llavors batlle de Barcelona, reté comptes de la seva administració al rei Pere el Catòlic, i entre els ingressos especificà el de la mostalafia, però sense concretar més ${ }^{33}$.

Que el pagaven els moros, quan es redimien, consta per la carta de manumissió atorgada per Pere de Sitjar - que era el lloctinent del batlle de Barcelona, Benvenist de Porta - al sarraí Mafumet, ex-captiu de Pere de Llissac, el 7 d'octubre de 1263. El moro pagà 10 sous de dret de mostalafia per la seva llibertat i fou autoritzat a marxar quan volgués i on volgués, o a romandre a Barcelona, si així ho volia ${ }^{34}$.

El segle XIV, aquest impost fou, segons David Romano, un impost de residència, tal com es defineix a través de les anotacions comptables dels registres de la secció del Mestre Racional. El pagaven cada any els moros francs que vivien a Barcelona i pujava a cinc sous per cap. Però també el pagaven quan sortien de Barcelona, juntament amb el dret de porta, que devia ésser en aquest moment l'impost característic de sortida ${ }^{35}$.

Malgrat tot, quan el 1354 el rei Pere el Cerimoniós volgué afavorir l'orde de la Mercè, li concedí franquícia de mostalafia per als captius sarraïns que tragués. Ignorem, però, si en aquest cas tenia només el sentit d'impost de sortida o bé si cal identificar-lo més

32 Cf. Apèndix, doc. 10.

33 ACA, C, pergamins de Pere el Catolic. 324.

34 ACB, pergamí 1-6-69.

35 D. RomANo, «Musulmanes residentes y emigrantes en la Barcelona de los siglos XIV-XV», Al-Andalus XLI (1976), pp. 49-86. 
aviat amb l'impost d'alliberament al qual hem fet referència abans $^{36}$.

L'impost, com s'esdevenia amb els altres, podia ésser obligat per pagar uns determinats deutes de la cort. El 1297 fou obligat, juntament amb la lleuda de les moles que sortien per mar i per terra de Barcelona, a Mateu Botella, a qui el rei havia promès donar un violari de 500 sous anuals. Abans d'aquesta data ja havia estat obligat a algú altre ${ }^{37}$.

Hom pot trobar xifres concretes del nombre de sarraïns que pagaren aquest impost $\mathrm{i}$ de les quantitats recaptades en diversos anys del segle XIV a l'estudi, ja citat, de David Romano ${ }^{38}$.

36 ACA, C, reg. 897, ff. 95 v. -96 r. (1354, abril, 27).

37 ACA, C. reg. 195, f. 111 r (1297, desembre, 28).

38 D. ROMANO, pp. 66-67. 


\section{APÈNDIX}

1105, mitjan abril.

El comte Ramon Berenguer III de Barcelona concedeix als jueus Mosse, Iafia, Honen i Abotaib l'exclusiva de portar a «Espanyas els sarraïns que es redimeixin dels qui es troben captius a les seves terres. Podran gaudir d'aquesta exclusiva mentre el comte no els retorni 12 lliures de plata que li han donat.

ACA, C, perg. de Ramon Berenguer III, núm. $91(20 \times 17,5 \mathrm{~cm})$.

Ed. F. FITA, Judios alfaqueques de sarracenos en Barcelona, p. 332.

Hec est donatio quam facit comes Remundus istis IIII or iudeis, id sunt Mosse et lafia, Honen et Abotaib.

Donat namque eis ut nulfus homo in omnem suam terram non ducat serracenum neque sarracenam ad Yspaniam per redemptionem nisi isti iudei, et nullus homo iudeus neque christianus non vadat in illorum navem per mercatum, si non fuerit voluntas eorum aut per illorum manum, et qui hoc eis fregerit, det comiti libram I auri, et postea hec datio fidelis permaneat. Et hoc teneant tantum quousque recuperant inde XIIm libras plate.

Sign+um Raimundi comes.

Sig+num Remundi Ermengod. Sig+num Remundi Guillelmi. Sig+num Bernardi Ollegarii, qui hoc scripsit, anno XLV Philippi, mediante mensis aprilis.

1144 , gener, 12

Ramon Berenguer IV dóna al mercader barceloní Arnau Pere d'Arcs la mostalafia per 150 morabatins d'or, 50 dels quals podran ésser recuperats del dret que el comte retenia en la dita mostalafia. 
ACB, Pergamins, 1-5-111 (22,5 x 19,5 cm). Trasllat de 1198.

Ed. Colección de documentos inéditos del Archivo General de la Corona de Aragón, IV, doc. XXXIX, a partir d'un trasllat de 1208 conservat a I'ACA.

Hoc est translatum scripture donationis de amoctalafia, cuius series scripture sic se habet.

Cunctorum noticie sit manifestum qualiter ego, Raimundus, Dei gracia Barchinonensium comes et marchio et Aragonensium regni inclitus dominator, dono tibi Arnallo Petri de Archubus totam ipsam amoctalafiam integriter et sine ulla diminutione, salvis meis directis que recto usatico mihi inde exire debent, ut tu eam habeas et teneas in sana pace potenter et integriter et omnes qui per te et per tuam vocem ad comodum tuum tuamque utilitatem in eadem amoctalafia fuerint tibi et tuis secure et quiete eam possideant. Et nichil amplius in prefata amoctalafia a te repetere possim nec te inde aliquo modo reptare nisi te exinde mihi culpabilem judicialiter comprobare valerem. Accipio quoque a te pro hac donacione $C L$ morabetinos. Quorum predictorum mora-betinorum recuperes $L$ morabetinos de meo recto usatico eiusdem amoctalafie sine tuo enganno. Si ego aut aliquis meorum hec tibi infringero vel infringerint ea que a te accipio ad comodum tuum de te adquisitore duppliciter emendem vel emendent et postea hec donatio firma permaneat omni tempore.

Que est acta II idus januarii, anno VII regni Ledoyci junioris.

Signum + Raimundi comes. Signum + Guillelmi Raimundi senescale. Signum + Bernardi de Bellog. Signum + Guillelmi de Subirads. Signum + Guillelmi Poncii. Sig +num Bernardi Marcucii. Sig+num Raimundi Marcucii. Sig+num Bernardi Poncii, Sig+num Petri presbiteri, qui hec scripsit cum litteris emendatis in linea VII, die et anno quo supra.

Sig + num Bernardi presbiteri. Sig + num Bernardi Poncii

Sig + num Bernardi Arberti Poncii.

Sig + num Raimundi presbiteri. Nos qui huic translationi presentes adfuimus.

Sig +num Petri de Corron, scriptoris, qui hec translatum scripsit XIII kalendas julii, anno Domini MCXCVIII. 
1178, novembre, Barcelona.

El rei Alfons el Trobador dóna a Bernat Marcús i als seus successors, per 500 sous, la facultat de negociar la redempció dels captius sarraïns que es trobin als seus regnes i comtats i de portar-los amb la seva nau a Bugia, Ceuta o altres terres sarraïnes. Podrà negociar igualment la redempció dels captius cristians en terres sarraïnes per tornar-los a terres cristianes.

ACB, Cartes reials 52-2. Perg. $(19,5 \times 21 \mathrm{~cm})$. Trasllat del 1184.

Hoc est translatum, fideliter translatum. Notum sit cunctis quod ego 11defonsus, Dei gratia rex aragonensis, comes Barchinone atque marchio Provincie, dono atque in perpetuum concedo tibi Bernardo Marcucii, progeniei atque posteritati tue, quod libere et sine contradictione alicuius hominis tibi facta possis ducere, per te vel per tuos, homines captivos in Chistianiam in tuo vexello vel in navi de toto regno et comitatibus meis undecumque velis, et possis scilicet abstrahere de terra christianorum et nostra auctoritate secure ducere in terra sarracenorum et reducere per mare et per totam meam terram. Et ipsi sarraceni et omnes alii qui fuerint in meo comitatu vel in comitatu meorum hominum sint salvi et securi in eundo et redeundo. Et, quando tua navis fuerit parata ad eundum, non detineatur nec contradicatur a baiulis nostris. Supradictam autem donationem facio tibi Bernardo Marcucii et tuis generationi atque posteritati tue. sicut superius scriptum est, semper in perpetuum, sicut melius dici vel nominari possit ad tuum tuorumque salvamentum sine engan. Preterea volo quod tu vel tui possitis redimere sarracenos per totam terram meam et ducere in terra sarracenorum sine ulla contrarietate, scilicet in Bugea et in Cepta et in omni alia terra sarracenorum et similiter omnes christianos redemptos possis abstradere de omni terra sarracerorum ${ }^{6}$ et adducere in terra christianorum. Accipio a te pro hac donatione $D$ solidos monete bone Barchinone.

Facta carta apud Barchinonam, mense novembris, anno Domini MCLXXYIII.

Signum (signe) lldefonsi regis Aragonis, comitis Barchinone atque marchio Provincie.

+ Berengarius, sancte Terrachone ecclesie archiepiscopus. Sig +num Bernardi de Calidis.

Sig + num Berengarii de Parietibus, notarii domini regis, qui hec eius mandato scripsit, mense et anno quo supra. Litteris rasis et emendatis linea $I I^{a}$ et $V^{\alpha}$. 
Signum (signe) Raimundi Berengarii. Signum + Gaufridi de Carrofa. Signum + Berengarii Pictoris. Nos ad huic translationi presentes adfuimus.

Sig(signe)num Petri de Corron, scriptoris, qui hunc translatum fideliter scripsit V kalendas septembris, anno Domini MCLXXXIII, cum litteris suprapositis in linea XIII.

a $\mathrm{et}$ similiter ... sarracenorum interlineat.

\section{IV}

1184 , juny, 1.

Ramon de Montcada i la seva muller Ramona i llur fill Ramon cedeixen a Arnau de Robió i als seus germans, Guillem i Berenguer, la quarta part de les eixees de Tortosa i de València amb caràcter vitalici.

ACA, C, pergs. d'Alfons I nủm. 368. (17,5 x 15,2 cm)

Sit notum cunctis quod ego Raimundus de Moncada et uxor mea Raimunda et filius mei Raimundus donamus vobis Arnaldo de Robyon et fratribus vestris Guillelmo et Berengario quartam partem exeam de Tortosa et quartam partem exeam Valencie omnibus diebus vite vestre. Sine omni obstaculo que ibi nil faciet et sine malo ingenio quod vos et vestri deductis illa via Valencie omnibus diebus vite vestre et essetis fidelis ex nostra parte nobis in omnia. Quod ego Raimundus de Moncada et uxor mea Remunda venimus cum vos Arnaldo de Robyon et cum fratri tuo Willelmo ad finem et ad pacificacionem de omnia exea que olim tenebatis per me vel per meis ut sumus vestri pagati bene per omnia secula. Quod ad huc convenimus vobis esse garitores et defensores de istam exeam contra omnibus personis ita quod superius scriptum est. Hec vobis faciamus tenere et habere in pacem omnibus diebus vite vestre. Si quis hec fregerit nil valeat sed firmum permaneat.

Actum est hec kalendis iunii, anno Domini $M^{\circ} \mathrm{C}^{\circ}$ LXXXIII $^{\circ}$

(Signe) Raimundi de Montecatano".

Sig +num Raimundi fili eorum.

Sig + num Raimunde uxoris eius nos qui hec laudamus et firmamus.

Sig+num Raimundi de Sentelles. Sig +num Gilbert. Sig +num Willelmi de Spluga. Sig +num Raimundi de Zabadia. Sig+num Petri de R. Ramon, Sig +num Arnal Garidel. Sig + num Mor [...]. 
Sig(signe)num Johannis de Podio, qui hec scripsit die et anno que supra.

a signatura autògrafa.

\section{V}

1185, abril, Barcelona.

El rei Alfons, comte de Barcelona i marquès de Provença, dóna en perpetuittat a Bernat Marcús i a Bernat Adarró la mostalafia de tota la seva terra que tindran per ell, de manera que ningú sinó ells, o sense llur consentiment, no podrà treure i portar captius sarraïns de la seva terra a terra sarraina. Els seus batlles no els podran impedir que vagin amb qualsevol vaixell que tinguin preparat. Els concedeix salconduit a ells $i$ als seus homes en anar $i$ venir.

En queda exclosa la mostalafia de València, que va donar i reté de Tarragona a Tortosa.

ACB, pergs. 1-2-140. $(27 \times 25 \mathrm{~cm})$. Trasllat del 1185 .

Hoc est translatum fideliter fachum. Notum sit cunctis quod ego Ildefonsus Dei gratia rex Aragonum, comes Barchinone et marchio Provincie, dono atque in perpetuum concedo tibi Bernardo Marcucii et Bernardo Adaronis et vestris totam illam meam almaztalafiam tocius mee terre, quam vos et vestri habeatis et teneatis per me et per meos potenter et sine contradictione per omnia loca vel ali scilicet modo quod nullus preter vos possit extrahere vel ducere captivos sarracenos de tota terra mea in terra sarracenorum nisi assensu et voluntate vestra. Preterea mando et dono vobis licencia quod nullus meus baiulus vel alius homo possit vobis contradicere vel vetare quin eatis vos et vestri quandocumque vestri vexelli parati fuerint. Preterea recipio in mea protectione et deffensione et in meo securo ducatu omnes homines qui vobiscum vel in vestris vexellis vel cum vestris hominibus ierint in eundo et redeundo per mare et per terram dum ibi remanere voluerint ita quod nullus sit ausus eos in aliquo gravare vel perturbare sed sint et vadant salvi et securi per omnia loca. Qui autem hoc meum donum et mandatum disrumperet iram meam incurret et erit cum omnibus suis rebus incurrumtus in meo posse et mando omnibus meis baiulis et vicariis ut hoc totum faciant vobis compleri et vetent quod nullus sit ausus hoc contradicere in aliquo, excepto hoc quod non sit in hoc con- 
veniencia vel dono illa almoztolafia Valencie quam dedi et retineo de Terrachona usque ad Dertosam et insuper hec omnia supradicta semper maneant firma.

Acfa carta apud Barchinonam, mense aprilis, anno Domini $M^{\circ} \mathrm{C}^{\circ}$ LXXX' Vo. Signum (signe) Ildefonsi, regis Aragonum, comitis Barchinone et marchionis Provincie.

+ Berengarius Terrachonensius archiepiscopus.

Ego Bernardus Barchinone episcopus subscribo.

Sig +num Bernardi de Pinel. Petrus sacrista Barchinone. Sig(signe)num Guillelmi Aimerici, vicarii Barchinone.

Sig(signe)num Berengarii de Parietibus, notarii domini regis, qui hanc cartam eius mandato scripsit.

Sig +num Guillelmi presbiteri. Geraldi presbiteri (signe). Sig(signe)num Geralli presbiter. Sig(signe)num Johannis levite.

Signum (signe) Guillelmi presbiteri, qui hec translatum fideliter scripsit II idus iunii, anno Domini $M^{o} C^{o}$ LXXXVo.

\section{VI}

1198, abril, 1. Tarragona.

Pere el Catòlic concedeix i confirma a Berenguera Adarró la mostalafia que el seu avi, el comte de Barcelona, donà a Amau Pere d'Arcs, avi seu. Ella i els seus successors la posseiran de la manera establerta en aquell document. Haurà de servir el càrrec una persona discreta, que ho sàpiga fer en benefici d'ella i de la ciutat de Barcelona, a parer dels prohoms Berenguer Bou, Guillem Gruny, Bernat Roig i Joan Sala. Per la confirmació el rei ha rebut 50 morabetins.

\section{ACB, Cartes reials C- $1-25$, perg. $(22,3 \times 16,5 \mathrm{~cm})$}

Sit notum cunctis quod ego Petrus, Dei gratia rex Aragonum et comes Barchinone, concedo et confirmo tibi Berengarie de Adarrone donacionem ille mutalafie quo inclitus avus meus comes Barchinone, piisime recordacionis, concessit et donavit Arnaldo Petro de Archubus, avo tuo et suis hec modo, videlicet, ut illam donacionem tu et illi qui post te de iure eam pos. sidere debuerint habeatis, tenatis et possideatis illam prout in ipso instrumento a predicto comite avo tuo et suis concesso habetur et continetur. salvo jure meo et meorum, ita tamen quod in tenenda et servienda ipsa moztalafia statuas quemdam discretam personam que sciat et noscat ip- 
sam fideliter tenere et servire ad utilitatem meam et tocius civitatis Bar. chinone ad cognicionem horum proborum hominum Barchinone, scilicet Berengarius Bovis, Guillelmi Grunii, Bernardus Rubei et Johannis de Sala donec filius tuus aut alter de heredibus tuis, cui pertineat de jure huiusmodi donatio per se ipso possit regere et manutenere officium jamdicte mutalafie. Sciendum tamen est quod pro huiusmodi confirmacione accepi a te $L$ morabetinos.

Datum Terrachone, Ia die veneris aprilis per manum Johannis Beaxen, domini regis notarii et mandato eius scripta, anno Domini $\mathrm{M}^{\circ} \mathrm{C}^{\circ} \mathrm{XC}^{\circ} \mathrm{Vm} \mathrm{I}^{\circ}$

Signum (signe) Petri regis Aragonum et comitis Barchinone. Guillemus Ausonensis episcopus (signe)e. (Signe) Petrus Ausonensis sacristib, Sig + num Dalmacii de Crexello. Sig + num Bernardi de Portella.

Sig+num Petri Latronis. Sig+num Eximini de Baisa. Sig +num Michaelis de Lusia.

Signum (signe) Johannis Beaxenssis, domini regis notarii.

(Al marge inferior) Raimundus de Moitali et Jacobus Andreei, Berengarius de Montisiudei.

I Signatura autògrafa. $\mathrm{b}$ Ídem.

\section{VII}

1206, abril, 12.

Berenguera, muller de Bernat Adarró, dóna a Arnau Adarró, fill seu, arran del seu matrimoni, el seu esponsalici i a més la mostalafia de Barcelona i de València que té pel rei.

ACB, perg. 1-6-677 (12 x 27,5 cm).

Sit notum omnibus quod ego Berengaria, uxor Bernardi Adarroni, dono tibi Arnaldo Adarroni, filio meo, ad diem tuarum nuptiarum in hereditate tocium meum sponsalicium et omnia iura et acciones que et quas pro dicto sponsalicio vel aliquibus aliis modis habeo et habere debeo in bonis dicti mariti mei. Addo etiam tibi huic donationi amoztalafiam Barchinone et Valencie sicut melius habebo et habere debeo et per dominum regem teneo. Hec itaque omnia superius notata cum omnibus pertinentiis suis sono tibi ad diem tuarum muptiarum in hereditate ac ut melius dici potest ad tuum tuorumque salvamentum de meo iure in tuum tuorumque tuicio, dominium et potestatem ad habendum omnique tempore possidendum et ad omnem tuam tuorumque voluntatem faciendam sine vinculo ullius 
hominis vel femine et absque ullo meo meorumque retento, salvis tamen sirectis et senioratico domini rege in iam dicat amoztalafia. In qua amoztalafia nullum alium seniorem proclames nec facias, nisi dominum regem et suos baiulos. Siquis hec fregerit supra dicta in duplo componat, posteaque firmum maneat.

Actum est hoc II idus aprilis, anno MCCVI. Signum + Berengarie.

\section{VIII}

1206, abril, 14.

Arnau Adarró dóna a la seva mare Berenguera, amb caràcter vitalici, la mostalafia de Barcelona i de València, amb la condició que li'n pagui un cens de mitja lliura de cera cada any.

ACB, perg, 1-6-677 (12 x 27,5 cm).

Sit notum omnibus quod ego Arnaldus Adarron dono tibi Berengarie, matri mee, in vita tua totam ipsam amoçtalafiam Barchinone et Valencie sicut melius ex donacione tua habeo et teneo per dominum regem. Quam amoztalafiam tu et homines per te teneatis in vita tua, et salvis directis et senioratico domini regi possideatis eam sine ulla contrarietate. Sub tali condicione quod in vita tua annuatim in festo Pentecostes tribuas mihi vel meis per censum dicte amoztalafie mediam libram cere bone et recipientis. Post obitum vero tuum iam dicta amoztalafia revertatur in meum dominium vel meorum sine ulla inquietudine. Siquis hoc fregerit supradicta in duplo componat posteo que firmum maneat.

Actum est hoc XVIII kalendas madii, anno MCCVI.

Signum + Arnaldi Adarron, qui hoc laudo et firmo.

a revertatur, interlineat. 
1267, octubre, 18, Tarassona.

Jaume I concedeix a Joan Cambra, fill de Domingo Cambra, ciutadà de València, que després de la mort del seu pare tingui ell el càrrec d'eixea des d'aquesta ciutat fins a Múrcia, amb caràcter vitalici, i que pugui treure captius i portar la rècula personalment o mitjançant un substitut.

ACA, C, reg. 15, f. $67 \mathrm{v}$.

Ed. J. VINCKE, Königtum und Sklaverei während des 14. Jahrhunderts, p. 43 .

Al marge superior del document, en lletra del segle XVII: Joannis de Camera, civis Valentia.

Per nos et nostros damus et concedimus tibi Johanni de Camera, filio Dominici de Camera, civis Valencie, diebus omnibus vite tue exeaticum a civitate Valencia usque ad Murciam, ita quod post dies patris tui, qui munc tenet dictum exeaticum, habeas et possideas ipsum exeaticum dum vixeris, et possis tu vel tuus substitus extrahere captivos et ducere reucham salve et secure, recipientes te et quos tecum vel tuo substituto yerint in nostra proteccione et guidatico speciali, mandantes universis subditis nostris quod te habeant et recipiant pro exea et custodiant et defendant ab omni dampno et gravamine te et reucham. Dictum autem exeaticum teneas et habeas quamdiu vixeris et dum bene et difeliter in ispo officio te habebis, concedentes tibi quod, quicquid de dicto exeatico habere poteris de consuetudine vel de iure, habeas franche et libere tanquam tuum proprium ad faciendum inde tuas proprias voluntates.

Data Tirasone, $X V^{\circ}$ kalendas novembris, anno Domini $M^{\circ} C^{\circ} C^{\circ} X^{o}$ septimo.

\section{X}

1277, agost, 3. València.

El rei Pere el Gran confirma la concessió feta pel seu pare a Alí Abcocon i a Muhammad Abcocon, fills d'Tbrahim, sarraïns de Tànger, perquè, juntament amb Jaume Farfal, de València, siguin motolafs $i$ puguin treure captius sarrains dels seus regnes per portar-los a terres sarraines $i$ 
captius cristians de terres sarraïnes per portar-los a terres cristianes. Muhammad Abcocon podrà, a més, viure i comerciar a la ciutat de València.

ACA, C, reg. 40 , f. 4r.

Ed. J. VINCKE, Königtum und Sklaverei währand des 14. Jahrhunderts. pp. 43-44, parcialment.

Reg. J. MARTínez FERRANDO, Catálogo de la documentación relativa al antiguo reino de Valencia existente en los registros de la Cancillería real II. Pedro el Grande, Madrid, 1934, núm. 261.

Petrus, Dei gracia et cetera, fidelibus suis vicariis, baiulis, curiis, iusticiis, alcaydis, corsariis et marinariis et universis aliis officialibus et subditis nostris ad quod presentes littere pervenerint, salutem et graciam.

Sciatis quod placet nobis quod Ali Abcocon et Machomet Abcocon, filii Abrahim, sarraceni de Tangia, cum Jacobo Fartal de Valencia sint motholafi et possint sarracenos captivos extrahere et redimere de terra nostra et ducere ad terram sarraçenorum salve et secure et extrahere et redimere eciam christianos de terris sarracenorum et adducere ad terras christianorum salve et secure, secundum quod dominus rex pater noster felicis recordacionis istud eis concessit cum carta sua, ut in ea continetur. et quod dictus Mahometus cum uxore sua et familia sua possit stare infra muros civitatis Valencie cum omnibus rebus suis et mercimoniis et dictas merces possit exhonerare quocienscumque ed eam veniant in propria domo, ipso solvente ius consuetum et debitum nobis et officialibus nostris pro nobis. Quare mandamus vobis quatenus in eisdem rebus aut mercibus eorum vel captivis quos secum duxerint nullum malum faciatis vel fieri permitatis, immo eisdem prestatis in eundo, stando et redeundo securum transitum et ducatum.

Data Valencia III nonas augusti, anno Domini $\mathrm{M}^{\circ} \mathrm{CC}{ }^{\circ} \mathrm{LXX}$ septimo. 